\title{
Anacardic acid induces mitochondrial-mediated apoptosis in the A549 human lung adenocarcinoma cells
}

\author{
YEONG-AE SEONG ${ }^{1}$, PYUNG-GYUN SHIN ${ }^{2}$ and GUN-DO KIM ${ }^{1}$ \\ ${ }^{1}$ Department of Microbiology, College of Natural Sciences, Pukyong National University, Busan 608-737; \\ ${ }^{2}$ Mushroom Science Division, National Institute of Horticultural and Herbal Science, \\ Rural Development Administration, Eumseong 369-873, Republic of Korea
}

Received October 26, 2012; Accepted December 12, 2012

DOI: $10.3892 /$ ijo. 2013.1763

\begin{abstract}
Anacardic acid (AA) is a constituent of the cashew nut shell and is known as an inhibitor of nuclear factor- $\kappa \mathrm{B}$ $(\mathrm{NF}-\kappa \mathrm{B})$. We investigated the cytotoxicity of AA on cancer cells and more experiments to reveal the cell death mechanism focused on A549 lung adenocarcinoma cells for our interest in lung cancer. To examine the molecular mechanism of cell death in AA treated A549 cells, we performed experiments such as transmission electron microscopy (TEM), western blot analysis, fluorescence-activated cell sorting (FACS), genomic DNA extraction and staining with 4',6-diamidino-2-phenylindole (DAPI). For the first time we revealed that AA induces caspase-independent apoptosis with no inhibition of cytotoxicity by pan-caspase inhibitor, Z-VAD-fmk, in A549 cells. Our results showed the possibility of mitochondrial-mediated apoptosis through the activation of apoptosis-inducing factor (AIF) and an intrinsic pathway executioner such as cytochrome $c$. This study will be helpful in revealing the cell death mechanisms and in developing potential drugs for lung cancer using AA.
\end{abstract}

\section{Introduction}

According to the 2009 annual report from the National Cancer Institute (NCI), the rates of new diagnose and death from all cancers combined have declined significantly for men and women, but the incidence rate for lung cancer in women has increased.

Anacardic acid (2-hydroxy-6-pentadecylbenzoic acid, AA; Fig. 1) is a constituent of the shell of the cashew-nut (Anacardium occidentale) (1) and has been discovered in many plants including Ginkgo biloba (2). AA has a number of roles including the inhibition of lipid synthesis, enzyme activity

Correspondence to: Professor Gun-Do Kim, Department of Microbiology, College of Natural Sciences, Pukyong National University, 45 Yongso-ro, Nam-Gu, Busan 608-737, Republic of Korea E-mail: gundokim@pknu.ac.kr

Key words: apoptosis, anacardic acid, apoptosis inducing factor, lung cancer such as lipoxygenase, prostaglandin endoperoxide synthase and histone acetyltransferase and the expression of nuclear factor- $\kappa \mathrm{B}(\mathrm{NF}-\kappa \mathrm{B})$ as well as the activation of aurora kinase $\mathrm{A}$ (2-6). Additionally, AA has an antibacterial and anticancer effect $(7,8)$.

The name 'apoptosis' coined by Kerr et al is classified as a type I programmed cell death (PCD) (9). Apoptosis is a physiological process characterized by chromatin condensation, nuclear fragmentation, DNA fragmentation and final removal by phagocytosis (10). Cell death is frequently thought to be 'caspase-independent' when it is not suppressed by broad-spectrum caspase inhibitors such as N-benzyloxycarbonylVal-Ala-Asp-fluoromethylketone (Z-VAD-fmk). However, the efficiency of Z-VAD-fmk is different from caspases and it also inhibits calpains and cathepsins, especially at high concentrations $(10 \mu \mathrm{M})(10)$.

The main pathways of apoptosis are the death receptor pathway (extrinsic) and the mitochondrial pathway (intrinsic). When the apoptotic ligands bind to death receptors, the extrinsic pathway occurs through the activation of initiators such as caspases 8 and 10, and the activation of executioners, caspases 3, 6, and 7 resulting in DNA fragmentation (11-13). The mitochondrion is an essential mediator of the intrinsic pathway. The arrival of signals leading to changes in permeability of the outer mitochondrial membrane is the cause of the releasing intermitochondrial apoptotic molecules into the cytosol $(14,15)$. Cytochrome $c$, one of the best characterized pro-apoptotic molecules, leads to activation of caspases via the formation of the apoptosome (16). AIF, a phylogenetically conserved mitochondrial flavoprotein, also has a key role in apoptosis. When apoptosis is induced, AIF relocates from the mitochondria to the nucleus where it mediates chromatin condensation and large-scale DNA fragmentation $(17,18)$.

The experiments reported in this research were designed to investigate the cytotoxic effect on cancer cells and to find the potential cell signaling pathways leading to cell death on AA treated human lung adenocarcinoma A549 cells.

\section{Materials and methods}

Cell culture and reagents. A549 (human lung adenocarcinoma), HEK293 (human embryonic kidney cell), HepG2 and SK-Hep1 (human hepatocarcinoma) were purchased from the 


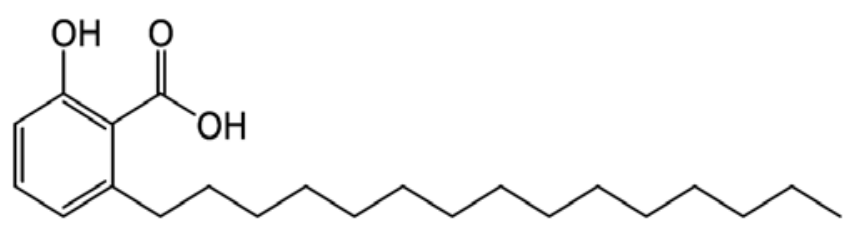

Figure 1. The structure of anacardic acid (AA, MW: 348.5).

American Tissue Culture Collection (Manassas, VA, USA). Cells were cultured in RPMI-1640 (A549), DMEM (HEK293), EMEM (HepG2 and SK-Hep1) (HyClone Laboratories, Logan, UT, USA) medium supplemented with $10 \%$ heat inactivated fetal bovine serum (FBS; HyClone Laboratories), $100 \mathrm{U} /$ $\mathrm{ml}$ penicillin and $10 \mu \mathrm{g} / \mathrm{ml}$ streptomycin (PAA Laboratories $\mathrm{GmbH}$, Pasching, Austria) in a humidified atmosphere containing $5 \% \mathrm{CO}_{2}$ at $37^{\circ} \mathrm{C}$. Except the cells were used in the cell viability, A549 cells were investigated, after incubation in the FBS-free RPMI-1640 medium for $24 \mathrm{~h}$, anacardic acid (AA), Calbiochem (San Diego, CA, USA) was added to the medium. Pan-caspase inhibitor, N-benzyloxycarbonyl-ValAla-Asp-fluoromethylketone (Z-VAD-fmk) was purchased from Sigma-Aldrich (St. Louis, MO, USA).

Cell cytoxicity. The exponential phase of cells were seeded into the wells of 96-well plates at an initial density of $0.5 \times 10^{5}-$ $1 \times 10^{5}$ cells in medium containing $10 \%$ FBS per well of $100 \mu 1$. Following $24 \mathrm{~h}$ of incubation, AA, dissolved in $100 \%$ dimethyl sulfoxide (DMSO; Sigma-Aldrich), was added to the culture medium at various concentrations. Cells were incubated for $24 \mathrm{~h}$ and $10 \mu \mathrm{l}$ of EZ-Cytox Cell Viability Assay Solution (WST-1 ${ }^{\mathrm{TM}}$; Daeil Lab Service, Seoul, Korea) was added and incubated for $4 \mathrm{~h}$ at $37^{\circ} \mathrm{C}$. The intensity was measured at $450 \mathrm{~nm}$ using an ELISA reader (Molecular Devices, Sunnyvale, CA, USA).

Western blot analysis. A549 cell lysates were prepared in a Radioimmunoprecipitation assay buffer (RIPA, Cell Signaling Technology, Danvers, MA, USA) and proteins were visualized using enhanced chemiluminescent (ECL) detection solution (Pierce Biotechnology, Rockford, IL, USA). Antibodies include anti-cleaved caspase 3, anti-cleaved caspase 7, anti-cytochrome $c$, anti-Bax, anti-Bad, anti-Bak, anti-Bcl-XL, anti-cleaved PARP, anti-FoxO1, anti-FoxO3a, anti-FoxO4, anti- $\beta$-actin, secondary rabbit and mouse antibodies conjugated with HRP were purchased from Cell Signaling Technology. Anti-AIF, antiHsp70, anti-polyclonal Hsp27, anti-Noxa, anti-STRAP, anti-Bim and secondary antibodies conjugated with HRP rabbit goat were purchased from Santa Cruz Biotechnology (Santa Cruz, CA, USA).

DAPI staining. 4',6-diamidino-2-phenylindole (DAPI) staining was used for the morphological observation of apoptosome. A549 cells were seeded in plates, and the cells were treated with or without AA $(3 \mu \mathrm{g} / \mathrm{ml})$ for $24 \mathrm{~h}$, then the cells were washed with PBS. Two-to-three milliliters of diluted DAPI was added to the cells and incubated for $15 \mathrm{~min}$ at $37^{\circ} \mathrm{C}$. The cells were rinsed once with methanol and the result was analyzed by fluorescence microscopy using an Eclipse 50i microscope.
TEM. For observation of more detailed morphological features, transmission electron microscopy (TEM) was used. Cultured A549 cells were pre-fixed in pellets at $4^{\circ} \mathrm{C}$ with $2.5 \%$ glutaraldehyde in $0.1 \mathrm{M}$ phosphate buffer and then post-fixed with $1 \%$ osmium tetraoxide $\left(\mathrm{OsO}_{4}\right)$ in $0.1 \mathrm{M}$ phosphate buffer, $\mathrm{pH}$ 7.4. After fixing, cells were embedded in Epon 812 using routine procedures. Approximately $70 \mu \mathrm{m}$ ultrasected specimens by Ultracut Reichert-jung were stained using uranyl acetate and lead citrate, and examined with Hitachi H600 TEM (Tokyo, Japan). All reagents used in the TEM experiment were purchased from Electron Microscopy Science (EMS).

FACS analysis. A549 cells were harvested by trypsinization and fixed with ice-cold ethanol $(70 \%)$ for $5 \mathrm{~h}$ at $4^{\circ} \mathrm{C}$. Followed resuspending with PBS containing RNase A $(0.2 \mu \mathrm{g} / \mathrm{ml})$ and incubation for $1 \mathrm{~h}$ at $37^{\circ} \mathrm{C}$. Cells were stained with propidium iodide $(40 \mu \mathrm{g} / \mathrm{ml})$ for $30 \mathrm{~min}$. The distribution of sub-G1 DNA content was analyzed using the FACS Calibur apparatus (Becton-Dickinson, Mountain View, CA, USA).

Genomic DNA extraction. For analyzing DNA fragmentation, genomic DNA was extracted using DNeasy Blood and Tissue kit purchased from Qiagen Inc. (Valencia, CA, USA) to the manufacturer's protocol.

\section{Results}

Cytotoxicity of $A A$. In order to investigate the cytotoxicity, we used a normal cells (HEK293), and lung (A549) and liver (HepG2, SK-Hep1) cancer cells were treated with AA in a dosedependent manner. After $24 \mathrm{~h}$ of exposure, the results of cell viability assay showed that AA inhibits the proliferation of all cells used. Although AA inhibited cellular proliferation of HEK cells, the cytotoxicity was less than cancer cells (Fig. 2A). To study the effect of the caspase inhibitor, cells were pretreated for $2 \mathrm{~h}$ with the cell-permeable and irreversible pan-caspase inhibitor Z-VAD-fmk $(100 \mu \mathrm{M})$ and then exposed to AA for $24 \mathrm{~h}$ in the continued presence of Z-VAD-fmk. Viability was then assessed by MTT assay using WST-1 ${ }^{\mathrm{TM}}$ and the result showed Z-VAD-fmk did not inhibit the cell viability in AA treated A549 cells (Fig. 2B). Considering our interest in lung cancer, we used A549 cells for further research and the $\mathrm{IC}_{50}$ value of AA treated A549 cells was $2.75 \pm 0.25 \mu \mathrm{g} / \mathrm{ml}$. Therefore, we used $3.0 \mu \mathrm{g} / \mathrm{ml}$ of AA for investigating the molecular mechanism of cell death in A549. Cellular morphology of AA treated A549 cells were shown under a microscope and cytotoxicity was increased dosedependently (Fig. 2C).

Induction of apoptosis in AA treated A549 cells. In order to further elucidate the nature of AA induced cell death in A549, we investigated the nuclear morphology of AA treated cells by using 4',6-diamidino-2-phenylindole (DAPI) staining. The results showed totally different patterns between the AA-treated and -untreated cells. AA treated cells exhibited formations of apoptosome (Fig. 3A-b), indicating that AA induces apoptosis in A549 cells. For further evidence of apoptosis, we analyzed the fragmentation of chromosomal DNA by using agarose gel electrophoresis (Fig. 3B). The fragmentation of chromosomal DNA by AA increased to the exposure time (Fig. 3B-b, c and d), while it was not observed 


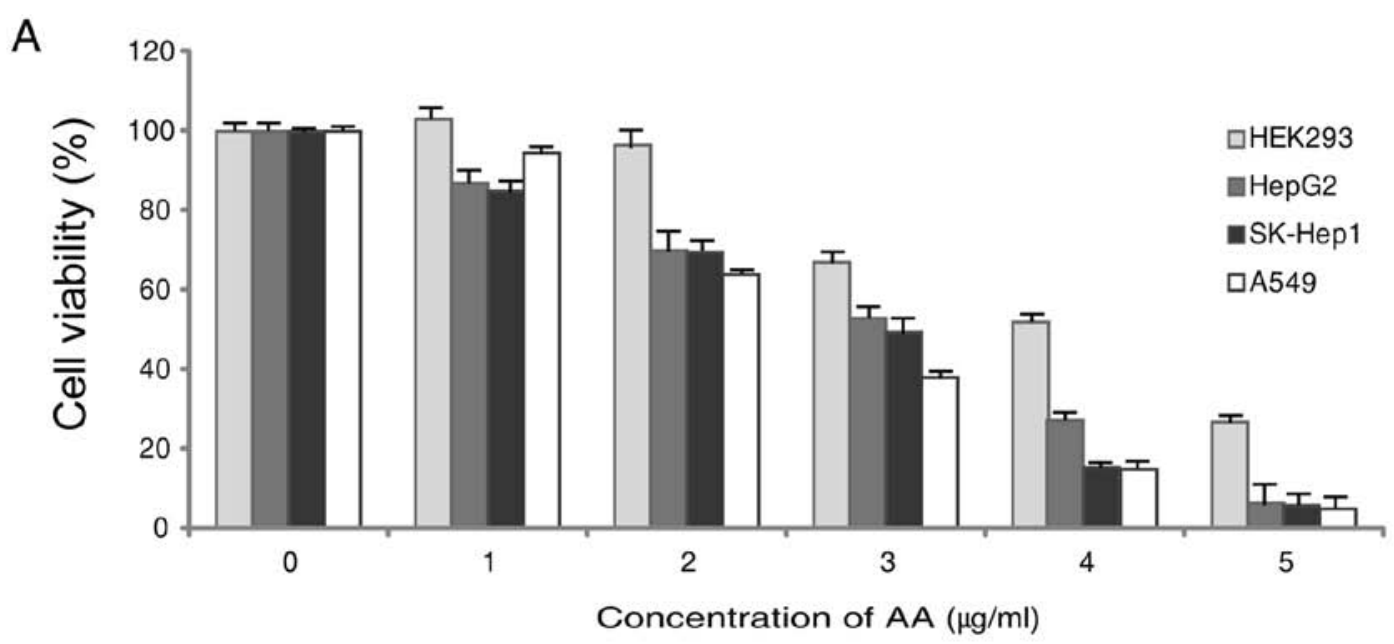

B

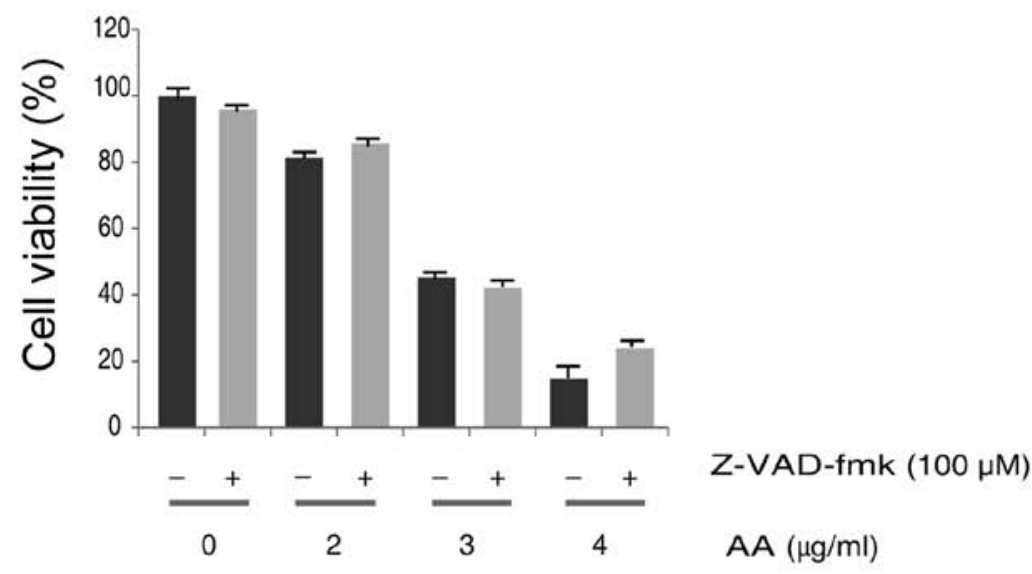

C
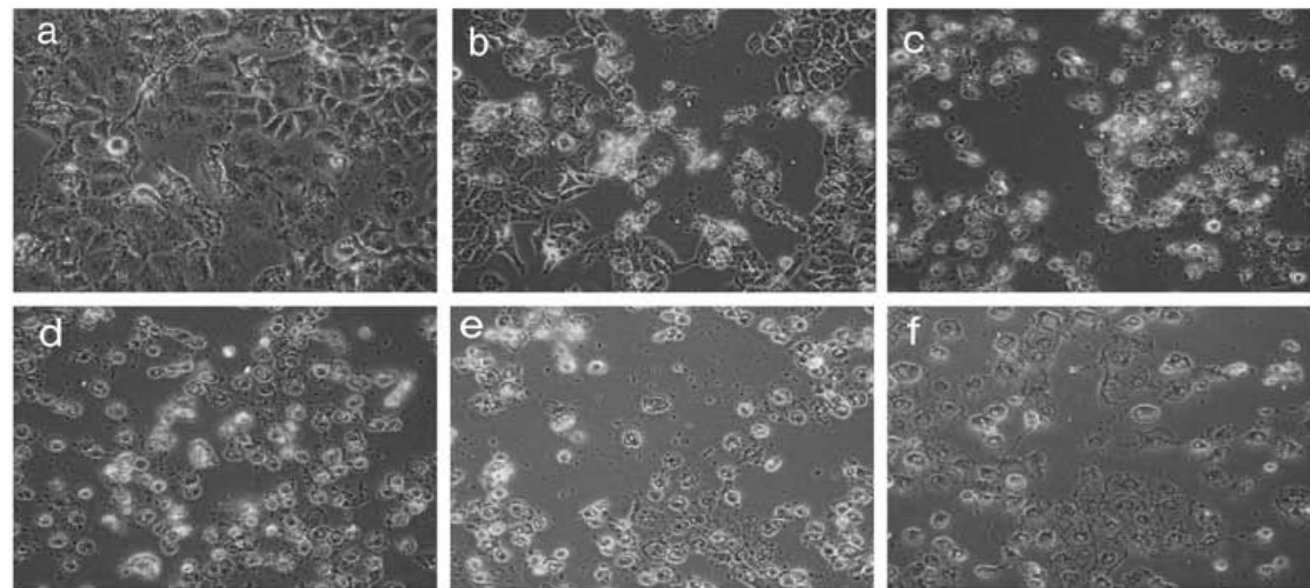

Figure 2. Cell viability in AA treated cell lines. (A) Cell viability was examined with a WST-1 assay. Cell growth was inhibited on a dose-dependent manner in AA treated cells. (B) The A549 cells were pretreated for $2 \mathrm{~h}$ with the cell-permeable, irreversible pancaspase inhibitor Z-VAD-fmk (100 $\mu \mathrm{M})$ and then $3.0 \mu \mathrm{g} / \mathrm{ml}$ of AA for $24 \mathrm{~h}$ in the continued presence of Z-VAD-fmk. Viability was then assessed by WST-1 assay. (C) A549 cells were incubated with AA for the indicated concentrations and analyzed under a microscope: (a) control cells; (b-f) 1.0, 2.0,3.0,4.0 and 5.0 $\mu \mathrm{g} / \mathrm{ml}$ of AA, respectively.

in the untreated cells (Fig. 3B-a). In addition, to study the cell death induced by AA, we quantified the sub-G1 DNA content by fluorescence activated cell sorting (FACS) analysis. The sub-G1 genomic DNA content was gradually increased after 6,12 and $24 \mathrm{~h}$ to $7.58,14.01$ and $38.79 \%$, respectively (Fig. 3C). TEM also showed apoptotic features such as chromatin condensation and nuclear fragmentation (Fig. 3D-b).
These results support the view that AA plays a major role in apoptosis induction in A549 cells.

Effect of AA on the intrinsic pathway of apoptosis in A549 cells. To determine the apoptosis signaling pathway induced by $\mathrm{AA}$, we analyzed the expression of several genes using western blot analysis. Cleaved caspase 3, cleaved caspase 7 and cyto- 
A

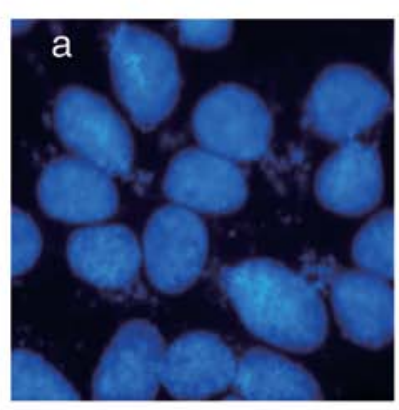

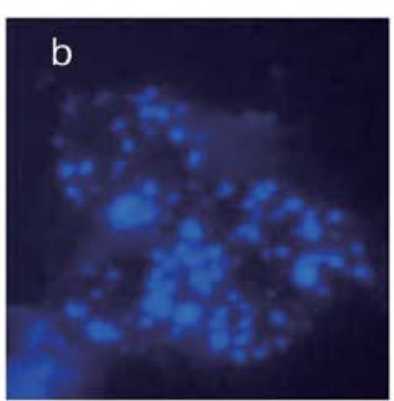

B

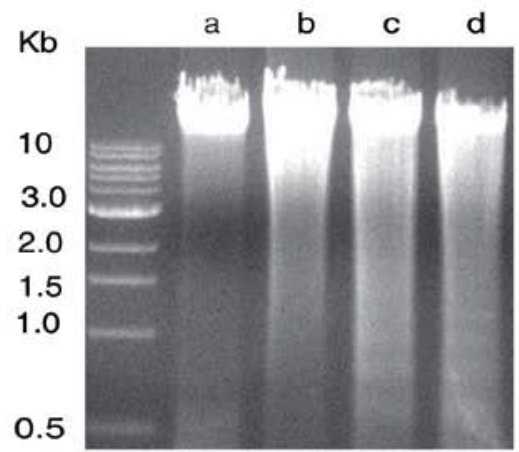

C
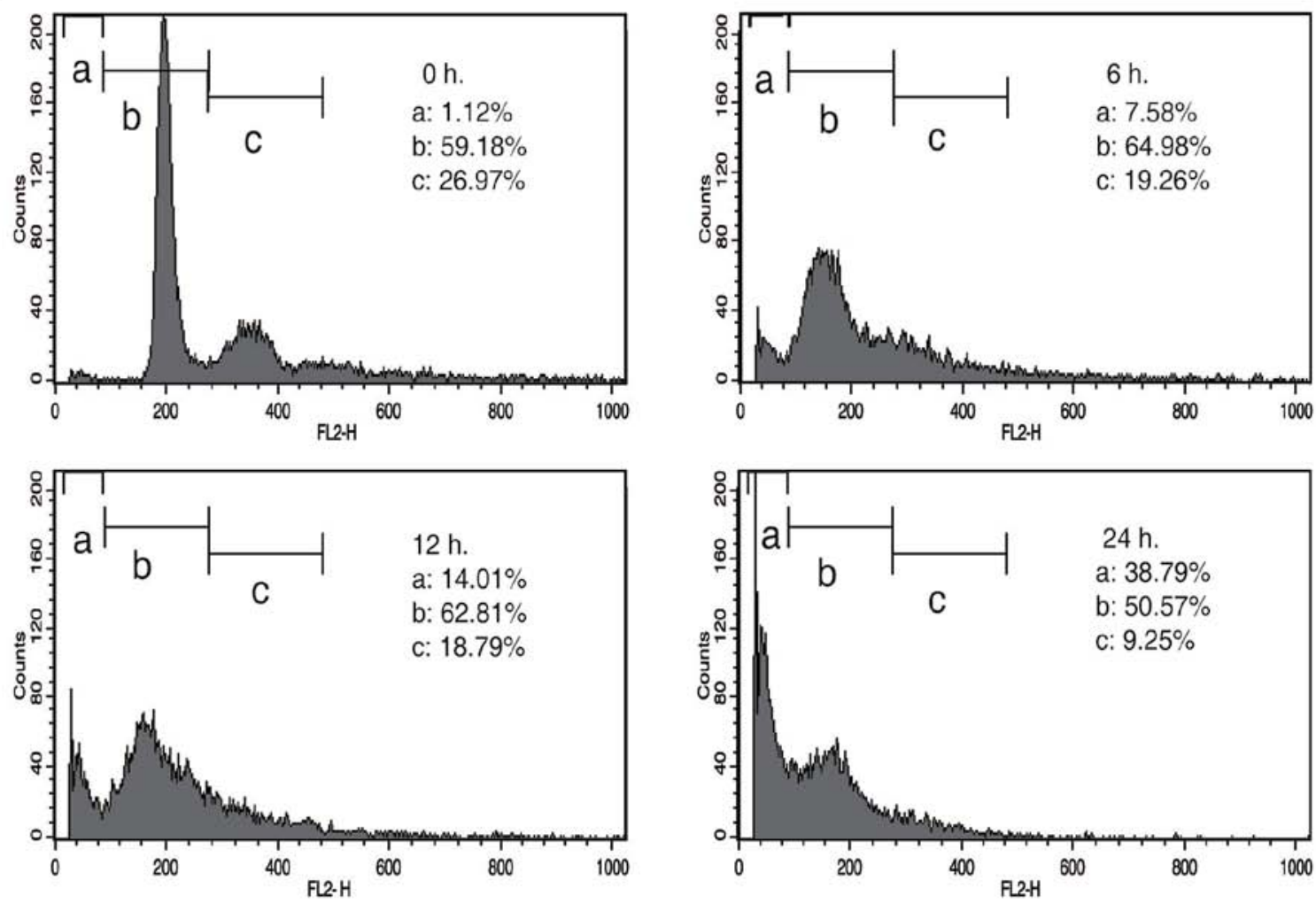

D
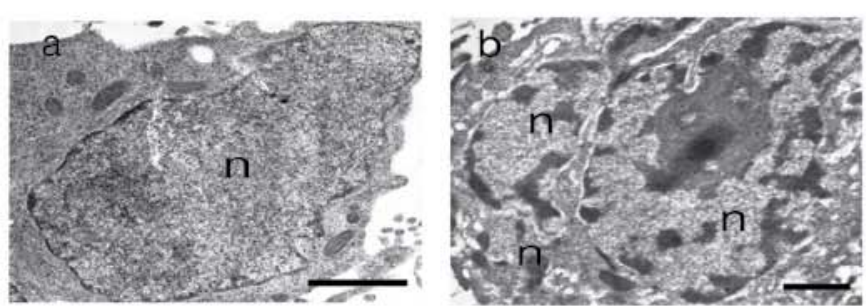

Figure 3. Induction of apoptosis in AA treated A549 cells. (A) The formation of apoptosome by AA was investigated by DAPI staining; (a) untreated cells; (b) apoptosome was seen in the cells treated with $3.0 \mu \mathrm{g} / \mathrm{ml}$ of AA for $24 \mathrm{~h}$. (B) DNA fragmentation assay; (a), untreated cells; (b-d) AA treated cells for 6, 12 and $24 \mathrm{~h}$, respectively. The results were obtained by $1.5 \%$ agarose gel electrophoresis. (C) Quantification of sub-G1 DNA content in A549 cells treated with $3.0 \mu \mathrm{g} / \mathrm{ml}$ of AA for 0, 6, 12 and $24 \mathrm{~h}$ were analyzed by FACS. (D) The induction of chromatin condensation and nuclear cleavage by AA were analyzed under TEM; (a) untreated cells; (b) cells treated with $3.0 \mu \mathrm{g} / \mathrm{ml}$ of AA for $24 \mathrm{~h} ; \mathrm{n}$, nuclear. Bars: a, b, $1 \mu \mathrm{m}$.

chrome $c$, known as the executioners of the intrinsic pathway, showed gradual increase in a time dependent manner on AA treated A549 cells. Caspase 9 was also analyzed (Fig. 4A). In addition, the expression of pro- and anti-apoptotic Bcl-2 family was determined. Pro-apoptotic members of the Bcl-2 family, Bim, Bad, Bak and Noxa increased, and the anti-apoptotic member Bcl-xL, decreased (Fig. 4B). The expression of Bak and Bad showed gradual increase time-dependently with AA-treatment and the expression of Bax and Noxa showed further increased level at $12 \mathrm{~h}$ after AA exposure. Bim has three isoforms (BimS, BimL and BimEL) with different intrinsic toxicities and promotes apoptosis (19). The cleaved form of Bim appeared at $6 \mathrm{~h}$ and the expression of Bcl-xl decreased gradually to $18 \mathrm{~h}$ after AA exposure. 
A

caspase 9
Cleaved
caspase 7
Cleaved
caspase 3
Gyt c

$\beta$-actin

C

AIF

Cleaved

PARP

$\beta$-actin

D

Hsp70
Strap
$\beta$-actin $\begin{array}{lllll}0 & 6 & 12 & 18 & 24\end{array}$

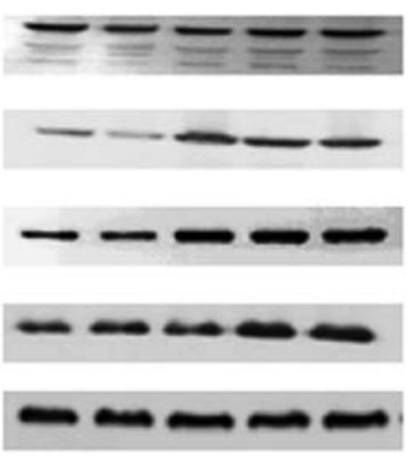

$\begin{array}{lllll}0 & 6 & 12 & 18 & 24\end{array}$

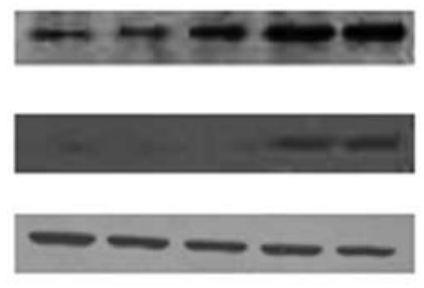

$\begin{array}{lllll}0 & 6 & 12 & 18 & 24\end{array}$

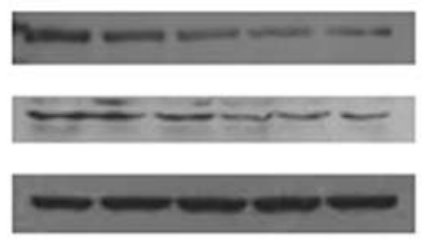

B

Bim

Bad

Bak

Noxa

Bax

BcI-XI

$\beta$-actin

E

$\begin{array}{lllll}0 & 6 & 12 & 18 & 24\end{array}$

FoxO3a

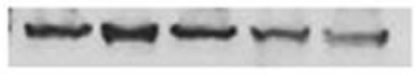

FoxO4

$\beta$-actin

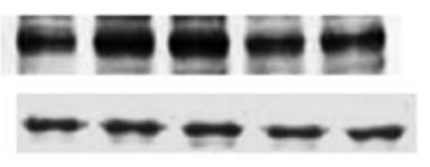

FoxO1

$\begin{array}{llll}0 & 6 & 12 & 24\end{array}$

$\beta$-actin $\begin{array}{lllll}0 & 6 & 12 & 18 & 24\end{array}$
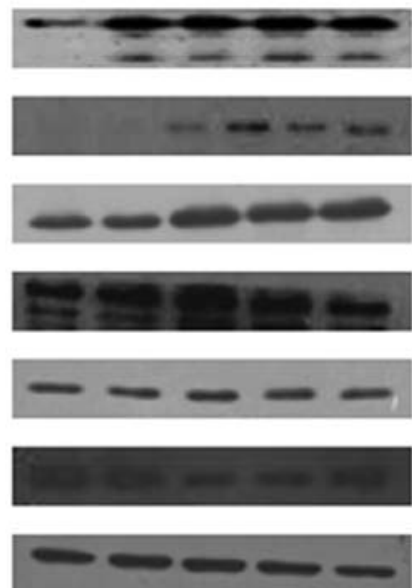

Figure 4. Time-dependent expression of apoptotic proteins in AA treated A549 cells. Whole-cell extracts were prepared and analyzed by western blotting. (A) Induction of intrinsic apoptosis pathway related proteins. (B) Expression of pro- and anti-apoptotic BCL-2 family proteins. (C) Expression of AIF and cleaved PARP. (D) Decrease of anti-apoptotic chaperone protein, Hsp70 and cofactor. (E) Expression of FoxOs.

Effects of AA on AIF related pathway. Because the inhibition of the pan-caspase inhibitor, Z-VAD-fmk, failed to prevent cell death, we analyzed the possibility of a caspase-independent pathway by apoptogenic molecules, apoptosis-inducing factor (AIF). Poly (ADP-ribose) polymerase-1 (PARP-1), the mediator of AIF release, was also investigated. The expression of AIF showed gradual increase, as did the cleaved PARP-1 after $18 \mathrm{~h}$ (Fig. 4C).

Decrease of the chaperone genes. We examined the expression of several genes that encode proteins known as molecular chaperones by assisting the correct folding of nascent and stress-accumulated misfolded proteins (20). We investigated the expression of Hsp70 and Strap, stress-responsive activator of p300 and the results showed downregulation of Hsp70 and Strap by AA (Fig. 4D).

Activation of forkhead transcription factors by AA. Members of the non-phosphorylated mammalian forkhead transcription factors (FoxOs) are involved in regulating the expression of genes involved in apoptosis. FoxO1, FoxO4 and FoxO3a are known as mammalian forkhead transcription factors that trigger the up-regulation of proteins such as Bim and NOXA (21). The expression of FoxO1, FoxO4 and FoxO3a in AA treated A549 cells increased with the optimal expression time being slightly different depending on the subfamily (Fig. 4E).

\section{Discussion}

The current study focused on the findings of a cell signaling pathway leading to death in A549 cells by AA. Our research provides strong evidence to support the view that AA induces apoptosis in a caspase-independent manner with no inhibition of cytotoxicity by pan-caspase inhibitor, Z-VAD-fmk, in A549 cells. In addition to the morphological features by TEM and microscopy and FACS analysis, the analysis of gene expression by western blotting demonstrates the induction of apoptosis by AA. 


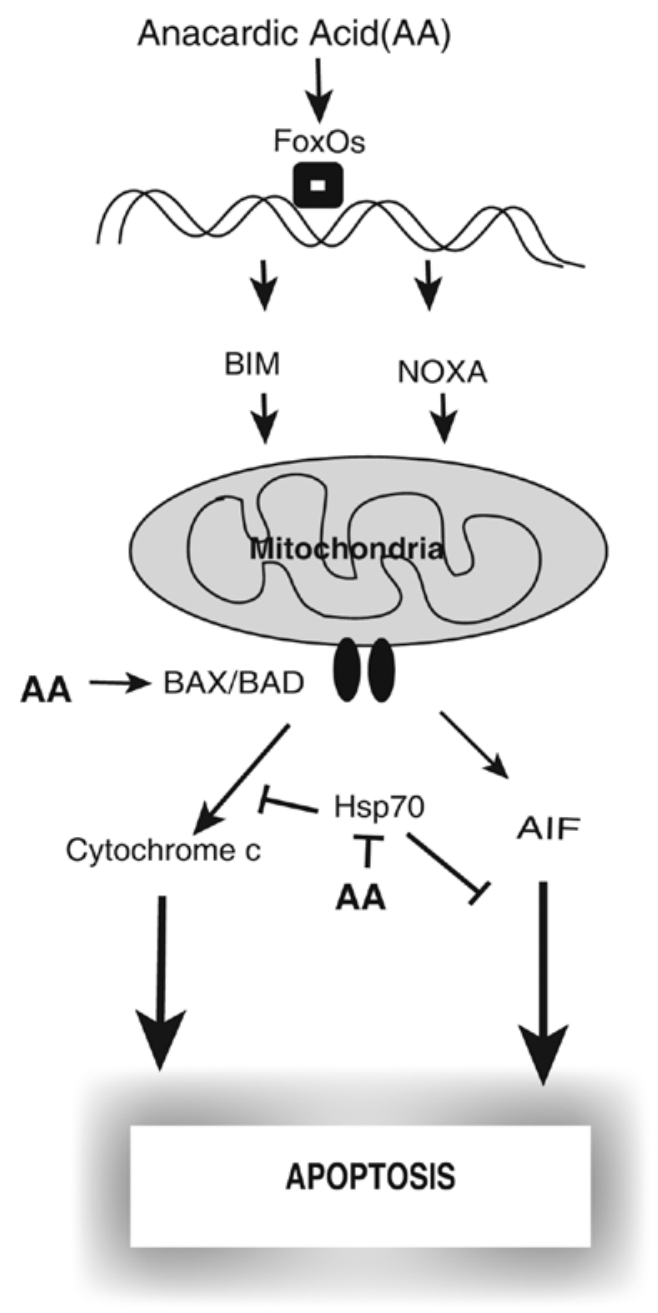

Figure 5. Potential apoptosis pathway of AA treated A549 cells. The release of the intermembrane proapoptotic factors from the mitochondria by imbalances between pro- and anti-apoptotic Bcl-2 family members, decrease of Hsp 70 and increase of AIF could have a key role in mitochondrial-mediated apoptosis in AA-treated A549 cells.

Previous research reported that the release of cytochrome $c$ from mitochondria is an early event during apoptosis, and pro-apoptotic Bcl-2 family members induce the release of cytochrome $c$ and anti-apoptotic $\mathrm{Bcl}-2$ proteins inhibit the release of cytochrome $c(22,23)$. The balance between the pro-apoptotic (Bid, Bad, Bim, Bax, Bak and Noxa) and anti-apoptotic (Bcl-2, Bcl-xL, A1 and Bcl-w) Bcl-2 protein families is an important factor contributing to cytochrome $c$ release, and in determining cell fate $(24,25)$. Following cytochrome $c$ release, caspases are activated and the cell undergoes apoptosis through the formation of apoptosomes, Apaf-1/caspase 9 complex (25). Bax and Bak are also known to promote apoptosis by modulating ER and mitochondrial $\mathrm{Ca}^{2+}$ stores (26). We are studying on the possibility of apoptosis by ER stress. The pro-apoptotic BH3-only protein Bim, induces cell death by binding the anti-apoptotic Bcl-2 family protein and Noxa is known as a mediator of p53-induced apoptosis (27). The expression of Bim and Noxa is regulated by the transcription factor of Forkhead (FKHR) in the rhabdomyosarcoma family including FoxO (21). FoxO transcription factors modulate the expression of genes involved in apoptosis, cell cycle, cell differentiation and other cellular functions (28). In this study, AA induced the expression of the pro-apoptotic Bcl-2 family proteins, Bim, Bad, Bak, Bax and Noxa and cytochrome $c$, and reduced the expression of the anti-apoptotic Bcl-2 family protein, Bcl-XL, in A549 cells. The expression of FoxOs increased on AA treated A549 cells. These results showed the possibility that the increase of pro-apoptotic BH3-only protein, Bim and Noxa by FoxOs and decrease of anti-apoptotic protein, Bcl-XL, induce the outer membrane disruption of mitochondria in AA treated A549. The disruption of mitochondria membrane may induce the release of proapoptotic mediators such as AIF and cytochrome $c$ from mitochondria.

Mitochondrial intermembrane flavoprotein AIF was originally characterized as a cell death mediator (17) and AIF has a potential role as a prognostic marker and a target for radiochemotherapeutic intervention in $\mathrm{CH} 27$ human lung carcinoma cells (29). AIF translocate from mitochondria to the cytosol and then move to the nucleus to cause peripheral chromatin condensation and large scale fragmentation of DNA $(17,18,30)$. AIF is an important mitochondrial protein involved in caspase-dependent and -independent pathways (31). One well-known mechanism to release AIF from mitochondria is by the activation of poly (ADP-ribose) polymerase-1 (PARP-1) which is a key molecule in AIF-induced cell death and mediates the release and translocation of AIF (32).

While PARP-1 is involved in the release of AIF from mitochondria (32), heat shock protein 70 (Hsp70) negatively regulates the AIF function by inhibiting translocation to the nucleus (33). Furthermore, Hsp70 inhibits apoptosis through the inhibition of a downstream pathway of cytochrome $c$ release, upstream of caspase 3 activation and Apaf-1 apoptosome formation (33-35). Hsps also block caspase-dependent and -independent apoptosis in Jurkat T cells (36) and a depletion of Hsp70 produces apoptosis-like death in various tumor cell types, including human oral carcinoma cells (37). Heat shock proteins are important prognostic factors in malignant diseases due to their abundant expression in many cancer cells. Strap is known as the Hsp70 transcription cofactor (38). Current results show the possibility that the decrease of Hsp70 and increase of proapoptotic protein AIF and PARP-1 promote chromatin condensation and DNA fragmentation and induce apoptosis in AA treated A549 cells.

In conclusion, for the first time our research suggests that AA induces caspase-independent apoptosis, that the pan-caspase inhibitor z-VAD-fmk does not inhibit cell death, and the activation of a mitochondrial-mediated cell death signaling pathway have a major role in apoptotic cell death in A549 cells. The release of the intermembrane proapoptotic factors from the mitochondria by imbalances between pro- and anti-apoptotic Bcl-2 family members, decrease of $\mathrm{Hsp} 70$ and increase of AIF could have a key role in apoptosis in AA treated A549 cells. Based on our results, we suggest (Fig. 5) the possible signaling pathway leading to apoptosis in AA treated A549.

\section{Acknowledgements}

This study was supported by a grant from the Next-Generation BioGreen 21 Program (SSAC, grant no. PJ008171), Rural Development Administration, Republic of Korea. 


\section{References}

1. Kubo I, Kinst-Hori I and Yokokawa Y: Tyrosinase inhibitor from Anacardium occidentale fruits. J Nat Prod 57: 545-551, 1994.

2. Murata M, Irie J and Homma S: Inhibition of lipid synthesis of bacteria, yeast and animal cells by anacardic acids, glycerol3 -phosphate dehydrogenase inhibitors from Ginkgo. Lebensm Wiss Technol 30: 458-463, 1997.

3. Grazzini R, Hesk D, Heininger E, et al: Inhibition of lipoxygenase and prostaglandin endoperoxide synthase by anacardic acids. Biochem Biophys Res Commun 176: 775-780, 1991.

4. Kishore AH, Vedamurthy BM, Mantelingu K, et al: Specific small-molecule activator of aurora kinase A induces autophosphorylation in a cell-free system. J Med Chem 28: 792-797, 2008 .

5. Sun Y, Jiang X, Chen S and Price BD: Inhibition of histone acetyltransferase activity by anacardic acid sensitizes tumor cells to ionizing radiation. FEBS Lett 580: 4353-4356, 2006.

6. Sung B, Pandey MK, Ahn KS, Yi T, Chaturvedi MM, Liu M and Aggarwal BB: Anacardic acid (6-nonadecyl salicylic acid), an inhibitor of histone acetyltransferase, suppresses expression of nuclear factor-kappaB-regulated gene products involved in cell survival, proliferation, invasion, and inflammation through inhibition of the inhibitory subunit of nuclear factor-kappaB alpha kinase, leading to potentiation of apoptosis. Blood 111 4880-4891, 2008

7. Choi JG, Jeong SI, Ku CS, Sathishkumar M, Lee JJ, Mun SP and Kim SM: Antibacterial activity of hydroxyalkenyl salicylic acids from sarcotesta of Ginkgo biloba against vancomycinresistant Enterococcus. Fitoterapia 80: 18-20, 2009.

8. Sukumari-Ramesh S, Singh N, Jensen MA, Dhandapani KM and Vender JR: Anacardic acid induces caspase-independent apoptosis and radiosensitizes pituitary adenoma cells J Neurosurg 114: 1681-1690, 2011

9. Kerr JF, Wyllie AH and Currie AR: Apoptosis: a basic biological phenomenon with wide-ranging implications in tissue kinetics. Br J Cancer 26: 239-257, 1972.

10. Kroemer G, Galluzzi L, Vandenabeele P, et al: Classification of cell death: recommendations of the Nomenclature Committee on Cell Death 2009. Cell Death Differ 16: 3-11, 2009.

11. Millan A and Huerta S: Apoptosis-inducing factor and colon cancer. J Surg Res 151: 163-170, 2009.

12. Slee EA, Adrain C and Martin SJ: Executioner caspase-3, -6, and -7 perform distinct, non-redundant roles during the demolition phase of apoptosis. J Biol Chem 276: 7320-7326, 2001

13. Walczak H and Krammer PH: The CD95 (APO-1/Fas) and the TRAIL (APO-2L) apoptosis systems. Exp Cell Res 256: 58-66, 2000.

14. Zamzami N, Susin SA, Marchetti P, Hirsch T, GómezMonterrey I, Castedo M and Kroemer G: Mitochondrial control of nuclear apoptosis. J Exp Med 183: 1533-1544, 1996.

15. Schultz DR and Harrington WJ Jr: Apoptosis: programmed cell death at a molecular level. Semin Arthritis Rheum 32: 345-369, 2003.

16. Adrain $\mathrm{C}$ and Martin SJ: The mitochondrial apoptosome: a killer unleashed by the cytochrome seas. Trends Biochem Sci 26: 390-397, 2001.

17. Susin SA, Lorenzo HK, Zamzami N, et al: Molecular characterization of mitochondrial apoptosis-inducing factor. Nature 397: 441-446, 1999.

18. Ye H, Cande C, Stephanou NC, et al: DNA binding is required for the apoptogenic action of apoptosis inducing factor. Nat Struct Biol 9: 680-684, 2002.
19. O'Connor L, Strasser A, O'Reilly LA, Hausmann G, Adams JM, Cory S and Huang DC: Bim: a novel member of the Bcl-2 family that promotes apoptosis. EMBO J 17: 384-395, 1998.

20. Beckmann RP, Mizzen LE and Welch WJ: Interaction of Hsp70 with newly synthesized proteins: implications for protein folding and assembly. Science 248: 850-854, 1990.

21. Obexer P, Geiger K, Ambros PF, Meister $B$ and Ausserlechner MJ: FKHRL1-mediated expression of Noxa and Bim induces apoptosis via the mitochondria in neuroblastoma cells. Cell Death Differ 14: 534-547, 2007.

22. Kluck RM, Bossy-Wetzel E, Green DR and Newmeyer DD: The release of cytochrome $\mathrm{c}$ from mitochondria: a primary site for Bcl-2 regulation of apoptosis. Science 275: 1132-1136, 1997.

23. Yang J, Liu X, Bhalla K, et al: Prevention of apoptosis by Bcl-2: release of cytochrome $\mathrm{c}$ from mitochondria blocked. Science 275: 1129-1132, 1997.

24. Green DR and Amarante-Mendes GP: The point of no return: mitochondria, caspases, and the commitment to cell death. Results Probl Cell Differ 24: 45-61, 1998.

25. Li P, Nijhawan D, Budihardjo I, Srinivasula SM, Ahmad M, Alnemri ES and Wang X: Cytochrome $\mathrm{c}$ and dATP-dependent formation of Apaf-1/caspase-9 complex initiates an apoptotic protease cascade. Cell 91: 479-489, 1997.

26. Nutt LK, Pataer A, Pahler J, Fang B, Roth J, McConkey DJ and Swisher SG: Bax and Bak promote apoptosis by modulating endoplasmic reticular and mitochondrial $\mathrm{Ca}^{2+}$ stores. J Biol Chem 277: 9219-9225, 2002.

27. Oda E, Ohki R, Murasawa H, et al: Noxa, a BH3-only member of the Bcl-2 family and candidate mediator of p53-induced apoptosis. Science 288: 1053-1058, 2000.

28. Huang $\mathrm{H}$ and Tindall DJ: Dynamic FoxO transcription factors. J Cell Sci 120: 2479-2487, 2007.

29. Leung HW, Wu CH, Lin $\mathrm{CH}$ and Lee HZ: Luteolin induced DNA damage leading to human lung squamous carcinoma CH27 cell apoptosis. Eur J Pharmacol 508: 77-83, 2005

30. Zhang X, Chen J, Graham SH, et al: Intranuclear localization of apoptosis-inducing factor (AIF) and large scale DNA fragmentation after traumatic brain injury in rats and in neuronal cultures exposed to peroxynitrite. J Neurochem 82: 181-191, 2002.

31. Cregan SP, Dawson VL and Slack RS: Role of AIF in caspasedependent and caspase-independent cell death. Oncogene 23: 2785-2796, 2004.

32. Yu SW, Wang H, Poitras MF, et al: Mediation of poly (ADP-ribose) polymerase-1-dependent cell death by apoptosisinducing factor. Science 297: 259-263, 2002

33. Gurbuxani S, Schmitt E, Cande C, et al: Heat shock protein 70 binding inhibits the nuclear import of apoptosis-inducing factor. Oncogene 22: 6669-6678, 2003.

34. Li CY, Lee JS, Ko YG, Kim JI and Seo JS: Heat shock protein 70 inhibits apoptosis downstream of cytochrome c release and upstream of caspase-3 activation. J Biol Chem 275: 25665-25671, 2000.

35. Saleh A, Srinivasula SM, Balkir L, Robbins PD and Alnemri ES: Negative regulation of the Apaf-1 apoptosome by Hsp70. Nat Cell Biol 2: 476-483, 2000

36. Creagh EM, Carmody RJ and Cotter TG: Heat shock protein 70 inhibits caspase-dependent and -independent apoptosis in Jurkat T cells. Exp Cell Res 257: 58-66, 2000.

37. Nylandsted J, Wick W, Hirt UA, et al: Eradication of glioblastoma, and breast and colon carcinoma xenografts by Hsp70 depletion. Cancer Res 62: 7139-7142, 2002.

38. Xu D, Zalmas LP and La Thangue NB: A transcription cofactor required for the heat-shock response. EMBO Rep 9: 662-669, 2008. 